\title{
Cervical Cancer screening in a tertiary care centre by Pap smear and its clinical correlation
}

\section{Girdhari Sharma ${ }^{1}$, Rajesh Adhikari ${ }^{1}$, Shyam Sundar Parajuly ${ }^{2}$, Kalpana Gautam Adhikari ${ }^{3}$}

${ }^{1}$ Department of Obstetrics and Gynecology, Pokhara Academy of Health Sciences, Western Regional Hospital \& Sahara International Fertility Centre, Pokhara ,Nepal

${ }^{2}$ Department of Radiology, Ultrasound Unit, Pokhara Academy of Health Sciences, Western Regional Hospital

${ }^{3}$ Department of Microbiology, Prithvi Narayan Campus, Pokhara Nepal

\section{Correspondence:}

Dr. Gir Dhari Sharma

Department of Obstetrics and Gynecology, Pokhara Academy of Health Sciences, Western Regional Hospital \& Sahara International Fertility Centre, Pokhara, Nepal

Email:1gdsharma@gmail.com

Article received : $30^{\text {th }}$ Sept. 2018

Article accepted : $2^{\text {nd }}$ Oct. 2018

\section{ABSTRACT}

\section{Introduction:}

Cervical cancer is one of the common cancers in women and is a major public health problem all over the world. It has significant contribution to high mortality and morbidity. Preinvasive lesions spontaneously regress to normal, remain stable for a long time or progress to higher degree of dysplasia followed by carcinoma cervix. Materials And Method This was a hospital based retrospective study where 456 patients' records were reviewed. Pap smear was used as the screening tool for the detection of precancerous lesion among the women visiting Western Regional Hospital (WRH), Department of obstetrics and gynecology. Results: Among 456 patients screened, most of them were in the age group of 30-39 years $(42.8 \%)$ and were of parity $3(42.8 \%)$. Most of them had no risk factors for carcinoma cervix (54.4\%). Early marriage accounted for the highest risk of developing precancerous lesion (32.7\%). There were no carcinoma detected by Pap smear. The test was negative in $68.9 \%$, Low-grade Squamous Intraepithelial Lesion (LSIL) was detected in $5.9 \%$ and $2.9 \%$ had High-grade Squamous Intraepithelial Lesion (HSIL). Pap smear was sent for screening purpose in asymptomatic women (37.1\%) and among the symptomatic patients vaginal discharge was the most common indication of pap test (34.6\%). Conclusion: A Pap smear is reliable, simple, non-invasive, cost effective, and easy screening tool for detection of precancerous lesions in a woman.

Key Words: Cervical cancer, Pap smear, Screening

\section{INTRODUCTION:}

Cervical cancer is one of the common cancers in the women, second to the breast cancer. It has become the major public health problem all over the world as it significantly contributes to mortality and morbidity. High prevalence of cervical cancer may be due late detection, lack of awareness and inadequate treatment program in the country. It is the fifth most common cancer in the world after stomach, lungs, breast and large bowel cancers. ${ }^{1}$

Preinvasive lesions may spontaneously regress to normal, 
remain stable for a long time or progress to higher degree of dysplasia. Although few Cervical Intraepithelial Neoplasia (CIN) lesions have the potential to progress to frankly invasive cancer, neoplastic potential increase with CIN grade. ${ }^{2}$

In developing countries, cervical cancer is the most common gynecological cancer and one of the leading causes of cancer death among women. Nearly Four hundred thousands new cases of cervical cancer are diagnosed annually worldwide and $80 \%$ of them are diagnosed in developing countries. There are 1.7 million cases in the developing world and as many as 5-13 millions women have precancerous lesions. ${ }^{2}$

It is the leading cancer among women in developing countries like Nepal. ${ }^{3}$ Contributing factors which increase its prevalence include early marriage, multiple sexual partner, poor nutrition, prostitution, recurrent cervicitis, Human Papiloma Virus (HPV) infection. Late diagnosis at advance stage is difficult to manage. Therefore early detection at the premalignant stage is needed to reduce the mortality and morbidity.

Early detection and its management is a public health priority for carcinoma cervix. Different screening methods are used for the detection like Visual Inspection with Acetic acid (VIA), Visual Inspection with Lugole Iodine (VILI), Pap smear and HPV testing. ${ }^{3}$ Pap test is one of the reliable methods of early detection of cervical intraepithelial neoplasia and carcinoma of cervix. It is a sensitive and widely used test for early detection. ${ }^{1,2}$ Pap test can be done in out-patients basis. In most hospitals of Nepal there is no universal screening programe. Screening is usually done only in womens attending gynecology OPD with complaints like lower abdominal pain and foul smelling vaginal discharge. This study was done to measure the abnormal pap report among the patients visiting gynecology OPD of WRH.

\section{MATERIALS AND METHOD:}

After getting ethical clearance from Western Regional Hospital, Pokhara, Nepal, the data of all the patients of one year period between 16th July 2016 and 15th July 2017 was collected from cervical cancer screening and prevention (CCSP) register. Four hundred and fifty six patients' records were reviewed for the study. Records of patients attending gynecology OPD with the history of lower abdominal pain, whitish discharge, post-coital bleeding and asymptomatic patients were reviewed for the study. History regarding age at marriage, number of sexual partner, past history of Sexually Transmitted Infection (STI), and smoking were noted. Abdominal, per speculum and bimanual examination were done and pap smear were taken if the women were in menstrual period between $10^{\text {th }}$ to $20^{\text {th }}$ day. Known cases of carcinoma cervix, patient under radiotherapy and pregnant ladies were excluded from the study. For pap smear, the patients were kept in lithotomy position and a pervaginal bivalve selfretaining Cusco speculum was inserted to visualize the cervix. Sample was taken from the ectocervix with a cytobrush after rotating a wooden Ayre spatula $360^{\circ}$. The sample was quickly smeared onto a labeled glass slide and fixed with 95\% ethyl alcohol in a jar. The glass slides were sent to the department of pathology for cytopathological examination. Laboratory results were reported according to the new Bethesda System for Reporting Cervical Cytology 2014. The system broadly divided the lesions into those negative for intraepithelial neoplasia and with epithelial cell abnormalities (ECA) that include squamous and glandular cells. After pap smear, appropriate treatment of the patient was done.

RESULTS:

Different age group of patients visited for Pap smear (Table 1). Among this $39 \%$ belonged to age group of $30-39,36.6 \%$ patients were in the age group of $40-49$ years and $8.1 \%$ were in the age group of 20-29.

\section{Table 1: Distribution of age and the frequency}

\begin{tabular}{|l|l|}
\hline Age in years & Frequency \\
\hline $20-29$ & $37(8.1 \%)$ \\
\hline $30-39$ & $178(39 \%)$ \\
\hline $40-49$ & $167(36.6 \%)$ \\
\hline$>50$ & $74(16.2 \%)$ \\
\hline Total & 456 \\
\hline
\end{tabular}

Among the patients for pap smear,195 (42.8\%) had 3 children and 139(30.5\%) had 2 children.

Most of the patients were house wife $81.4 \%$ followed by students and job holder (10.3\% and 8.3\%) respectively. 
Table 2: Distribution by parity

\begin{tabular}{|l|l|}
\hline Parity & Frequency \\
\hline p1 & $47(10.3 \%)$ \\
\hline p2 & $139(30.5 \%)$ \\
\hline p3 & $195(42.8 \%)$ \\
\hline p4 & $52(11.4 \%)$ \\
\hline $5>$ & $23(5.0 \%)$ \\
\hline Total & 456 \\
\hline
\end{tabular}

Table 3: Occupation of the patients

\begin{tabular}{|c|c|}
\hline Occupation & Frequency \\
\hline Housewife & $371(81.4 \%)$ \\
\hline Student & $47(10.3 \%)$ \\
\hline Job & $38(8.3 \%)$ \\
\hline Total & 456 \\
\hline
\end{tabular}

Table 4: Risk factors for cervical cancer

\begin{tabular}{|l|l|}
\hline \multicolumn{1}{|c|}{ Risk Factors } & Frequency \\
\hline No identifiable risk & $248(54.4 \%)$ \\
\hline Early marriage & $149(32.7 \%)$ \\
\hline Multiple partners & $21(4.6 \%)$ \\
\hline Smoking & $20(4.4 \%)$ \\
\hline STI & $18(3.9 \%)$ \\
\hline Total & 456 \\
\hline
\end{tabular}

Among the patients $54.4 \%$ had no risk of cervical cancer. Most common risk factor was early marriage (32.7\%).

Among the reports obtained of Pap smear, most were negative for malignancy $(68.9 \%)$, followed by inflammatory smear (15.4\%).

Table 5: Report of Pap smear $(n=456)$.

\begin{tabular}{|l|l|}
\hline Pap Report & Frequency \\
\hline Negative & $314(68.9 \%)$ \\
\hline Inflammatory & $70(15.4 \%)$ \\
\hline $\begin{array}{l}\text { Atypical Squamous Cells of } \\
\text { Undetermined Significance(ASCUS) }\end{array}$ & $32(7.0 \%)$ \\
\hline LSIL & $27(5.9 \%)$ \\
\hline HSIL & $13(2.9 \%)$ \\
\hline
\end{tabular}

Most of the patients had vaginal discharge (34.6\%) followed by abdominal pain (16.9\%).
Table 6: Symptoms and Pap smear $(n=456)$.

\begin{tabular}{|l|l|}
\hline Symptoms & Frequency \\
\hline Vaginal discharge & $158(34.6 \%)$ \\
\hline Abdominal pain & $77(16.9 \%)$ \\
\hline Post coital bleeding & $52(11.4 \%)$ \\
\hline Asymptomatic & $169(37.1 \%)$ \\
\hline
\end{tabular}

\section{DISCUSSION:}

The cervical cancer screening was done most commonly at the age of 30 to 39 years (39\%) and least was done in 20 to 29 years of age $(8.1 \%)$ in our study. Sachan et al in their study on cervical cancer screening using pap smear test with clinical correlation of one year duration among 1650 sexually active women found that common age of screening was after 21 years and most common age group was 31 to 40 years. These findings are comparable with our study. ${ }^{4}$ In another study done by Makuza et al on prevalence and risk factors of cervical cancer and precancerous lesion in Rwanda, the mean age was 37.0 years. ${ }^{5}$ The high incidence of screening at 30-40 years of age may be due to knowledge regarding screening opportunities for carcinoma cervix at this age. In our study, parity 3 women $42.8 \%(\mathrm{n}=195)$ were screened more than other parity.

Immune suppression during pregnancy, hormonal influences on cervical epithelium, and physical trauma related to vaginal deliveries have been suggested as etiological factors associated with development of cervical neoplasia. ${ }^{6}$ Sachan et al also found that para three or more had cervical pathology screened among 1650 sexually active women. ${ }^{4} \quad$ In our study $54.4 \%($ $\mathrm{n}=248$ ) of the cases screened had no risk factors. Early marriage with early exposure to sexual activity consisted $32 \%(n=149)$. Early marriage still persists in our society due to conservative beliefs. Multiple sexual partner $4.6 \%$ $(\mathrm{n}=21)$, smoking $4.4 \%(\mathrm{n}=20)$ and sexually transmitted disease also contributed as risk factors.

Early Age at First Sexual intercourse (AFSI) has long been associated with an increased risk of invasive cervical carcinoma (ICC). AFSI and AFP are strongly interrelated in most developing countries. A pooled analysis of case-control studies on ICC from eight developing countries with 1864 cases and 1719 controls investigated the roles of AFSI, AFP, and ICC risk. Age 
at first sexual intercourse, AFP and age at first marriage

(AFM) were highly interrelated and had similar ICC risk estimates. They included a series of case-control studies on ICC from eight developing countries. ${ }^{7}$

A study done in rural area of China among 1315 women aged 21-68 years showed that there is significant association between smoking and cervical lesions. Chemical carcinogens in tobacco, such as cotinine and nicotine were found to exist in cervical mucosa of smoking women, probably exerting a series of carcinogenic effects by activating nitrosamines and causing DNA damage. This in turn may destroy the local immune defense in the cervical epithelium. Thus, smoking has a serious impact on the development of cervical lesions consistent with findings indicating that smoking cessation benefits CIN regression. ${ }^{8}$

In our study, clients presenting with vaginal discharge were $34.6 \%$, abdominal pain $16.9 \%$, post coital bleeding $11.4 \%$ and $37.1 \%$ were asymptomatic. A systemic review of 2012 by Gillet et al about association between bacterial vaginosis and CIN suggested that Bacterial Vaginosis (BV) is the most common vaginal disorder among women of reproductive age which plays a role in cervical carcinogenesis. It has been noted that cervical cytological abnormalities are found significantly more often in women with a disturbed vaginal flora, suggesting a possible link between $\mathrm{BV}$ and the development of cervical cancer. ${ }^{9}$ Sachan et al studied about the symptoms of women attending gynecological OPD in 1650 clients, where $15.1 \%$ were asymptomatic, whitish discharge was present in $36.9 \%$, pain abdomen in $26.6 \%$ and post coital bleeding in 3.09\%. ${ }^{4}$

A study done by Misra et al in 503 women with PID showed squamous Intra epithelial lesion of high grade as $28.6 \%$ but there was no case of carcinoma. ${ }^{10}$ In a prospective study conducted at Department of Obstetrics and Gynaecology, Santosh Medical College, Ghaziabad from January 2016 to November 2016 among 75 patients attending the gynaecology OPD with postcoital bleeding and a control group of 75 asymptomatic women found that majority of the CIN lesions can be detected by cervical screening. ${ }^{11}$

Regarding the report of Pap smear, our study demonstrated negative result in $68.9 \%(\mathrm{n}=314)$, inflammatory in $15.4 \%(\mathrm{n}=70)$, ASCUS in $7 \%(\mathrm{n}=32)$, LSIL in $5.9 \%$ $(\mathrm{n}=27)$, HSIL in $2.9 \%(\mathrm{n}=13)$. On histopathological examination cervical intraepithelial neoplasm (CIN) 1 was found in $14.6 \%$. High grade (CIN 2, 3) lesions were present in $10.7 \%$ cases with postcoital bleeding(PCB). There are several studies reporting the incidence of malignancy with PCB. ${ }^{5,6}$ In the study done by Tehranian et al. only one case of cervical cancer $(0.8 \%)$ and 3 cases of CIN 1 and CIN 3 (2.4\%) had been reported. ${ }^{12}$

In the study by Chandra et al in 2013, among 20,000 women, 125 women $(0.63 \%)$ had an unsatisfactory Pap test initially. These patients underwent repeat sampling to obtain the satisfactory results. Overall, 1,438 (7.19\%) women showed abnormal Pap cytology results, including 1,270 women $(6.35 \%)$ with ASCUS, 7 women $(0.04 \%)$ with atypical squamous cells which could not exclude high-grade squamous intraepithelial lesion (ASC-H), 125 women $(0.63 \%)$ with low-grade squamous intraepithelial lesion (LSIL), 32 women $(0.16 \%)$ with high-grade squamous intraepithelial lesion (HSIL), 2 women $(0.01 \%)$ with squamous cervical carcinoma (SCC), and 2 women $(0.01 \%)$ with atypical glandular cells (AGC). A total of 18,562 women (92.81\%) women tested negative for intraepithelial lesion or malignancy. ${ }^{13}$ The prospective study done in a department of Pathology of a tertiary hospital among total of 4160 cases found that most common cause for unsatisfactory smear was obscuring inflammation (55.3\%) where more than 75\% of epithelial cells are obscured. In the same study,34.2\% cases showed absence of endocervical/ transformation zone component and $10.5 \%$ showed obscuring blood, $87.9 \%$ cases were Negative for Intraepithelal Lesion or Malignancy. Epithelial cell abnormalities were seen in $0.5 \%$ cases which include LSIL $(0.2 \%)$, HSIL $(0.2 \%)$ and ASCUS (0.1\%). LSIL was most commonly seen in reproductive age group (20- 45 years) and HSIL was most commonly seen in peri menopausal age group (4655 years $).{ }^{14}$

In another study among 20,000 women, 125 women $(0.63 \%)$ had an unsatisfactory Pap test initially. Overall, 1,438 (7.19\%) women showed abnormal Pap cytology results, including 1,270 women (6.35\%) with ASC-US, 7 women $(0.04 \%)$ with atypical squamous cells. Total 125 women $(0.63 \%)$ had (LSIL), 32 women $(0.16 \%)$ had (HSIL), 2 women (0.01\%) had (SCC), and 2 women $(0.01 \%)$ had atypical glandular cells (AGC). A total of 
18,562 women $(92.81 \%)$ women tested negative for intraepithelial lesion or malignancy (NILM) ${ }^{15}$

\section{CONCLUSION:}

Pap smear is the best method of screening for carcinoma cervix. It is reliable, simple, non-invasive, cost effective, and easy screening tool for detection of precancerous lesions in a woman, however detection can only be done with the facility of pathologist.

\section{REFERENCES:}

1. Pradhan N, Giri K, Rana AN. Cervical Cytological study in unhealthy and healthy looking cervix. J Obstet.Gyaecol. 2007;2(2):42-7.

2. Mandakini M Patel, Amrish N Pandya, Jigna Modi. Cervical Pap Smear Study And utility In Cancer Screening, to specify the strategy for Cervical cancer control. National Journal of Community Medicine. 2011;2(1):49-1.

3. Tamrakar SR, Chawala CD. A Clinical Audit of Pap Smear Test for screening of Cervical Cancer. NJOG. 2012'7(2):21-4.

4. Sachan PL, Singh M, Patel ML, Sachan R. A Study on Cervical Cancer Screening Using Pap Smear Test and Clinical Correlation. Asia-Pacific Journal of Oncology Nursing. 2018;5(3):337-41.

5. Makuza JD, Nsanzimana S, Muhimpundu MA, Pace LE, Ntaganira J, Riedel DJ. Prevalence and risk factors for cervical cancer and pre-cancerous lesions in Rwanda. The Pan African Medical Journal. 2015;12:26.

6. Babara L Hoffman, John O Schorge, Joseph I Schaffer, Lisa M Halvorson ,Karen M Bradshaw,F.Gary Cunningham. Williums Gynecology Second edition copyright 2012 p 738-756.

7. K.S Luise,S de Sanjose,M Dias,S Castalsague, R Herrero,C J Meijor . Early Age at First Sexual Intercourse and Early Pregnancy are risk factors for cervical cancer in developing countries. British Journal of Cancer 2009; 100(7); 1191-97.

8. Qinqwe Zhang,Wenjen Xie,Feng Wang, Pong Hong Li,Lina Cui,Huifen Wang et al. Epidemiological Investigation and Risk Factors for Cervical Lesion, Cervical cancer Screening among women in rural area of Henen Province of China. Med Sci Monit 2016; 22:1856-65;

9. Gillet E, Meys JFA, Verstraelen $\mathrm{H}$, et al. Association between Bacterial Vaginosis and Cervical Intraepithelial Neoplasia: Systematic Review and Meta-Analysis. Atashili J, ed. PLoS ONE. 2012; 7(10):e45201.

10. Misra JS, Srivastava AN, Sharique A, Srivastava KR. Cervical Cytology Associated with Pelvic Inflammatory Diseases. J Cytol Histol. 2015; 6:343.

11. Gupta M, Sharma A, Agrawal N, Agrawal A. Clinical Profile of Women with Postcoital Bleeding. Santosh University Journal of Health Science. 2016;2(2);106-8.

12. Hende Celik,Mehmetoglu Ganime,Sadikoglu, Alis Ozcakir,Nazam Bilgel. Pap Smear Screening in the Primary Health Care Setting Study from Turkey. N AM Med Sci. 2010 (10) 467-472.

13. CM Das, Shah Nasreen, Ghori Ambreen, Khursheed Farkhunda, Zaheen Zakia. Prevalence and Risk Factors for Cervical Intraepithelial Neoplasia in Patients attending Gynecological Outpatient Department of Tertiary Care Hospital. Liaquat Uni Med Health Sci. 2013; 12(1):44-8.

14. Pudasaini S, Prasad KBR. Cervical pap smear- A prospective study in a tertiary hospital. Journal of pathology of Nepal. 2015;5:820-23.

15. Wang Z, Wang J, Fan J, et al. Risk factors for cervical intraepithelial neoplasia and cervical cancer in Chinese women: large study in Jiexiu, Shanxi Province, China. Journal of Cancer. 2017;8(6):924-932. 